\title{
Evaluation of Future East Asia Drought Using Multi-Model Ensemble
}

Jae-Won Choi*, Yumi Cha and Jeoung-Yun Kim

National Institute of Meteorological Sciences, 33, Seohobuk-ro, Jeju 63568, Korea

*Corresponding author: Jae-Won Choi, National Institute of Meteorological Sciences, 33, Seohobuk-ro, Jeju 63568, Korea, Tel: +86-10-82995018; E-mail: choikiseon@daum.net

Received date: Nov 09, 2016; Accepted date: Dec 23, 2016; Published date: Dec 29, 2016

Copyright: (C) 2016 Choi JW, et al. This is an open-access article distributed under the terms of the Creative Commons Attribution License, which permits unrestricted use, distribution, and reproduction in any medium, provided the original author and source are credited.

\begin{abstract}
We analyzed the changes in precipitation and drought climatology over East Asia by global warming using the daily precipitation data from 14 coupled atmosphere-ocean general circulation model simulations under the Special Report on Emission Scenarios (SRES) A1B scenario at the end of the twenty-first century. The models were consistent in predicting an increase in the mean precipitation over East Asia. However, the increase was less significant in Southeast Asia, and was accompanied by even larger increase in precipitation variability. This predicted precipitation climatology was translated into a change in drought climatology using the effective drought index (EDI). According to the increased precipitation, East Asia tends to be wetter with a decreased frequency and duration of drought. However, because of the enhanced precipitation variability, extreme droughts are predicted to be more frequent, especially over Southeast Asia.
\end{abstract}

Keywords: Precipitation; Drought; East Asia; Global warming; Effective drought index

\section{Introduction}

A report from the Intergovernmental Panel on Climate Change [1] indicated that East Asian water resources are threatened by an enhanced variability in the precipitation under global warming. However, few studies have tried to estimate quantitatively the hydrological disasters that we should expect. This study has an interest on drought which caused by precipitation deficits over a prolonged period.

Several modeling studies have shown that over Asian monsoon regions, increases in greenhouse gas concentrations lead not only to an increase in mean precipitation but also to a significant enhancement in precipitation variability on sub-seasonal to inter-annual timescales [2-4]. The significance of these findings was verified by recent studies using the Multi-Model Ensemble (MME) method [3,5,6]. The results showed that the frequency of non-precipitation increases in a way that is similar to the frequency of heavy rainfall [3]. Monsoon excesses and deficiencies are also projected to intensify [5]. However, it remains to be understood how drought patterns are affected by the enhanced variability of precipitation.

Some of the studies on future drought were interested in the global scale dryness revealed by changes in soil moisture conditions [7-9] or Palmer Drought Severity Index [10,11]. However, the predictions for the magnitude and extent of dryness in East Asia are considerably different in each study. For example, Manabe et al. [8] predicted dryer conditions while Burk et al. [10] predicted wetter conditions. One reason for these different results could be the use of different Global Circulation Models (GCMs). Due to the strong model dependence of the hydrological response to a greenhouse gas increase, different models may predict changes with different signs, even for the same region and the same variable. Moreover, climate sensitivity also differs substantially among models. The MME averaging approach can be very useful in reducing the uncertainties related to model dependence.
Although this method is widely used to investigate the future climate, only a single study [12] has attempted to evaluate the likelihood of future drought. That study used 15 state-of-the-art GCMs. Furthermore, there is another limitation. Most of them derived their results by comparing the climatologically averaged values of presentday and future. This simple comparison can only measure the climatological dryness and/or wetness but fail to catch the actual drought change, which is an extreme natural phenomenon with very irregular time scales.

This study examined the impact of greenhouse gas warming on East Asian drought by comparing the projected climate (2081-2100) in the Special Report on Emission Scenarios (SRES) A1B experiment with the present-day control climate (1981-2000). The projected daily precipitation data were translated into drought climatology by using the effective drought index (EDI) [13], which quantifies the drought intensity in daily time steps. We used the MME average from 14 GCMs and assessed its roughness.

\section{Models and Methods}

\section{Models}

The 14 GCMs used this study are a part of the IPCC's data archives at the Lawrence Livermore National Laboratory. All of the models begin their integration from the "20th Century Climate in Coupled Model" run, in which the level of anthropogenic forcing is based on historical data from the late 19th century through the 20th century. From the end of the 20C3M run, SRES A1B conditions were imposed and integrated through the year 2100. The SRES A1B assumes rapid economic and population growths that peak mid-century and decline thereafter. Two time periods of twenty years each were chosen for analysis: the late 20th century (1981-2000; hereafter 20C3M) and the late 21st century (2081-2100; hereafter A1B). The analysis based on the 14 GCMs and their MME average (average of 14 GCMs). The following model data were used in this study: CCSM3, CGCM3.1 (T47), CGCM3.1 (T63), CNRM-CM3, CSIRO-Mk3.0, ECHAM5/MPI- 
OM, FGOALS-g1.0, GFDL-CM2.0, GFDL-CM2.1, GISS-AOM, INMCM3.0, MIROC3.2 (hires), MIROC3.2 (medres), and MRICGCM2.3.2. Model characteristics for all components and other details are available at http://www-pcmdi.llnl.gov/ipcc/ model_documentation/. In addition, characteristics on advantages or disadvantages of these models can be found some previous studies $[7,14,15]$.

In addition to the differences in the parameterization of the physical and dynamical processes, the models also differ from each other in their spatial resolution. The resolutions of the 14 models range from coarse (e.g., $4^{\circ} \times 5^{\circ}$ for the GISS-AOM) to fine (e.g., $1.4^{\circ} \times 1.4^{\circ}$ in CCSM3). To obtain the MME pattern, the original model outputs were converted to the same resolution $\left(2.5^{\circ}\right.$ longitude/latitude $)$ by employing the bi-linear interpolation technique. Several studies have demonstrated that these models are capable of reproducing the temporal and spatial features of the East Asian precipitation climate $[7,14,15]$.

\section{Effective Drought Index (EDI)}

The EDI was applied to measure the drought. Unlike many other drought indices, the EDI is calculated with a daily time step.

$$
\mathrm{EP}_{\mathrm{i}}=\sum_{\mathrm{n}=1}^{\mathrm{i}}\left[\left(\sum_{\mathrm{m}=1}^{\mathrm{n}} \mathrm{P}_{\mathrm{m}}\right) / \mathrm{n}\right]
$$

\section{$\mathrm{DEP}=\mathrm{EP}-\mathrm{MEP}$}

\section{$\mathrm{EDI}=\mathrm{DEP} / \mathrm{ST}(\mathrm{DEP})$}

Where $\mathrm{Pm}$ is the precipitation $\mathrm{m}$ days before and the index $\mathrm{i}$ represents the duration of summations in days. Here $i=365$ is used; that is, the summation is equal to a year, which is the most dominant precipitation cycle worldwide. EP is the summed value of daily precipitation with a time dependant reduction function. DEP represents the deviation of EP from MEP (30-year average EP for the calendar date). ST (DEP) denotes the standard deviation of each day's DEP. EDI expresses the standardized deficit or surplus of stored water on a daily basis. It enables one location's drought severity to be compared to that of another location, regardless of climatic differences. The "drought range" of EDI indicates extreme drought at $\mathrm{EDI}<-2.5$, severe drought at $-1.5>\mathrm{EDI}>-2.49$, and moderate drought at $-0.7>\mathrm{EDI}>-1.49$. Near normal conditions are indicated by $0.69>\mathrm{EDI}>-0.69$. The use of EDI has been tested in several drought studies [16-20]. When using EDI to explore the changes in drought as a result of future climate scenarios, the calibration factors were set at present-day values.

\section{Results}

\section{Future precipitation climatology}

Figure la shows the area-averaged $\left(10^{\circ}-50^{\circ} \mathrm{N}, 100^{\circ}-140^{\circ} \mathrm{E}\right)$ percentage changes (Eqn. 2) of the mean and the standard deviation of precipitation data set for $14 \mathrm{GCMs}$.

$(\mathrm{A} 1 \mathrm{~B}-20 \mathrm{C} 3 \mathrm{M}) / 20 \mathrm{C} 3 \mathrm{M} \times 100$

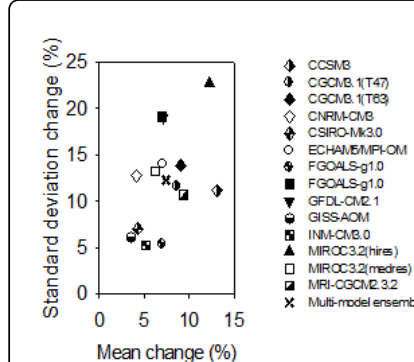

(a)

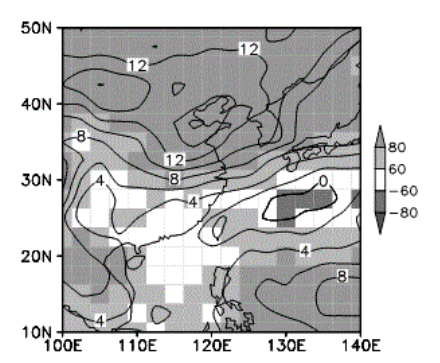

Figure 1: (a) Scatter plot of the area-averaged (East Asia; $10^{\circ}-50^{\circ} \mathrm{N}$, $100^{\circ}-140^{\circ} \mathrm{E}$ ) percentage change in the mean and the standard deviation of the precipitation data for 14 GCMs. The percentage change is defined as $100 \times(\mathrm{A} 1 \mathrm{~B}-20 \mathrm{C} 3 \mathrm{M}) / 20 \mathrm{C} 3 \mathrm{M}$. A multi-model ensemble value is denoted by the $\mathrm{X}$ symbol. (b) Multi-model ensemble percentage change in mean precipitation from the $20 \mathrm{C} 3 \mathrm{M}$ to the A1B experiments. Shading denotes the consistency level (\%) of the 14 models in predicting the direction of change in mean precipitation.

It is confirmed that the increase of precipitations in East Asia, mentioned in the introduction, is shown in all the 14 models used in this study. While the minimum increase is projected by GISS-AOM (3.56\%), the maximum increase is projected by CCSM3 (13.06\%). The increase of the MME average is $7.41 \%$. The increases in the standard deviation vary from $5.26 \%$ (INM-CM3.0) to $22.73 \%$ (MIROC3.2 (hires)), and the MME average is $12.28 \%$. In 12 out of 14 GCMs, the increase rate in the standard deviation is higher than that in the mean value. In the 4 GCMs (CNRM-CM3, MIROC3.2 (medres), GFDLCM2.1, GFDL-CM2.0), the increase rate in the standard deviation is over two times that in the mean. These mean that the increase in changeability of precipitation is more distinct than the increase in the average precipitation.

Figure $1 \mathrm{~b}$ shows the spatial distribution of the percentage changes of the MME average precipitation from the $20 \mathrm{C} 3 \mathrm{M}$ to the $\mathrm{A} 1 \mathrm{~B}$ experiments. To investigate its robustness, consistency level among models is calculated (shading). Here the consistency is defined as a fraction of the number of models with either positive or negative change: That is, the value is $+100 \%$ if all model have projected an increase, and is $-100 \%$ if all models have projected a decrease in the future compared to the present. The absolute value of consistency level is always larger than or equal to $50 \%$. In Northeast Asia above $30^{\circ} \mathrm{N}$, the increase rate of precipitation is $8-12 \%$, and the model consistency level is high. On the other hand, in the Southeast Asia below $30^{\circ} \mathrm{N}$, the increase rate is relatively low $(0-8 \%)$, and their model consistency level is low too.

Figure 2a shows the time-latitude cross-section of monthly mean precipitation averaged for $100^{\circ}-140^{\circ} \mathrm{E}$ for the MME of $20 \mathrm{C} 3 \mathrm{M}$ experiments. Figure $2 \mathrm{~b}$ shows the MME percentage changes from the $20 \mathrm{C} 3 \mathrm{M}$ to the $\mathrm{A} 1 \mathrm{~B}$ experiments and the corresponding consistency index (shading). The comparison of these two figures shows that the increase rate of precipitation is bigger as the latitude is higher and the season is colder. It is confirmed that the precipitation in the entire East Asia increases during summer, implying the strengthening of the East Asian summer monsoon. From the region around $30^{\circ} \mathrm{N}$ during winter to Southeast Asia during spring, the precipitation decreases a little. 


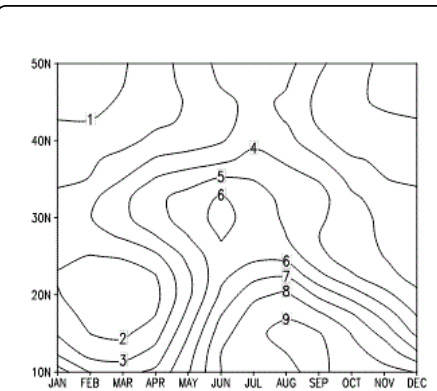

(a) $20 \mathrm{C} 3 \mathrm{M}$

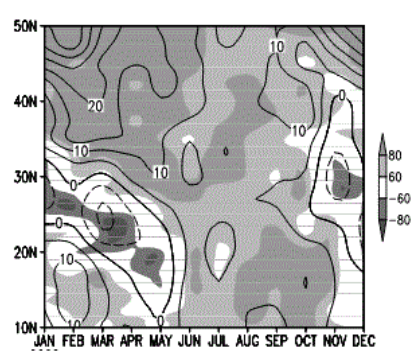

(b) $\mathrm{A} 1 \mathrm{~B}-20 \mathrm{C} 3 \mathrm{M}(\%)$
Figure 2: Latitude-time cross section of monthly mean precipitation averaged for $100^{\circ}-140^{\circ} \mathrm{E}$. (a) Multi-model ensemble for the $20 \mathrm{C} 3 \mathrm{M}$ experiments (unit: $\mathrm{mm} /$ day). (b) Multi-model ensemble percentage changes from the $20 \mathrm{C} 3 \mathrm{M}$ to the A1B experiments. Shading denotes the consistency level (\%) of the 14 models in predicting the direction of change in mean precipitation.

\section{Future drought climatology}

Figure 3 shows the difference in the frequency distribution of the EDI values over East Asia for 14 GCMs between the A1B and 20C3M experiments. EDI, originally, is a standardized index, follows normal distribution with zero mean. The frequency decrease of the negative values which means dryness and the frequency increase of positive values which means wetness are definitely shown in Figure 3. Hence, the center of EDI value frequency distribution moved toward wetness in the $\mathrm{A} 1 \mathrm{~B}$ experiments. In other words, frequency of wetness increases according to the overall precipitation increase in East Asia, and the frequency of dryness decreases. However, there is seen a special feature here. That is the increase of frequency of extreme values: below -2 and over +2 . This means that the hydrologic variability increases greatly in East Asia. That is, the frequencies of extreme flood increase at the same time, and the frequencies of extreme drought increase as well.

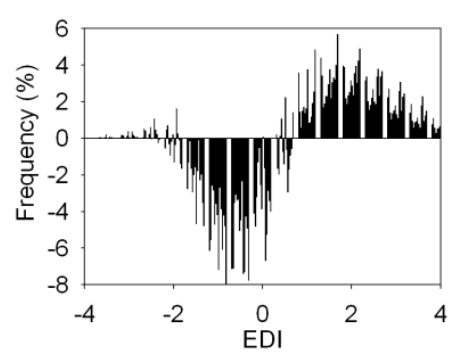

Figure 3: Difference in frequency distribution of EDI over East Asia for 14 GCMs between the A1B and 20C3M experiments.

Figure 4 shows the relationships between the intensity and duration of drought simulated by 14 GCMs in the $20 \mathrm{C} 3 \mathrm{M}$ and the $\mathrm{A} 1 \mathrm{~B}$ experiments. The drought duration herein is the consecutive days of negative EDI, and the drought intensity, the minimum EDI during the duration. The regression coefficients (c) which show the relationship of the two variables are indicated in the bottom of each panel. The percentage change of the number of total drought events from the $20 \mathrm{C} 3 \mathrm{M}$ to the A1B experiment is indicated in the top of the A1B panel.
As analyzed above, the frequency of drought decreases from $14.0 \%$ (GFDL-CM2.1) to $42.6 \%$ (CCSM3) according to the increased precipitation in East Asia. In 13 out of 14 models, on the other hand, the slope of the linear regression line is steeper in the A1B experiment than that was in the $20 \mathrm{C} 3 \mathrm{M}$ experiment. This means that the droughts in the future have tendency of intensive precipitation lack although the frequency and duration of drought decrease.

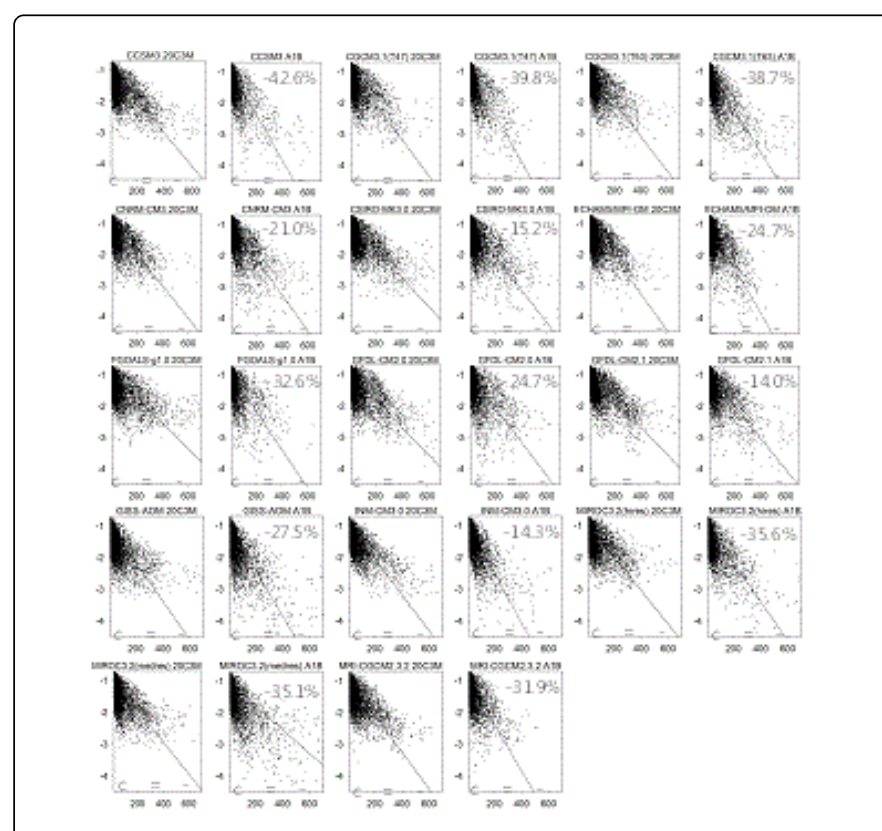

Figure 4: Scatter diagrams showing the relationship between the intensity and the duration of drought. The left scale shows the EDI values. The bottom scale shows the duration of drought (unit: days). The percentage change of the number of total drought events from the $20 \mathrm{C} 3 \mathrm{M}$ to the $\mathrm{A} 1 \mathrm{~B}$ experiment is shown in the upper part of the A1B panels. The regression coefficient $(\mathrm{C})$ is shown in the bottom part of the panels.

\section{Drought intensity}

Figure 5 displays the difference in MME total drought days (extreme $<-2.5<$ severe $<-1.5<$ moderate $<-0.7$ ) between the A1B and the $20 \mathrm{C} 3 \mathrm{M}$ experiments. The panels in the left are the spatial distribution (days/decade), and the panels in the right show the latitude-time cross sections of monthly total drought days (days/decade) averaged for $100^{\circ}-140^{\circ} \mathrm{E}$. In the horizontal spatial distribution, moderate drought days decrease in the entire East Asia, corresponding to the increased mean precipitation. The magnitude of the decrease is large in the Northeast Asia where the model consistency exceeds $80 \%$. Both the magnitude of the decrease and the model consistency level are relatively small in Southeast Asia. The drought days in Northeast Asia show a noticeable decrease during spring while in the Southeast Asia, the decrease is weak. At the latitude of $25^{\circ} \mathrm{N}$, there is a weak increase of drought days in April and May. 


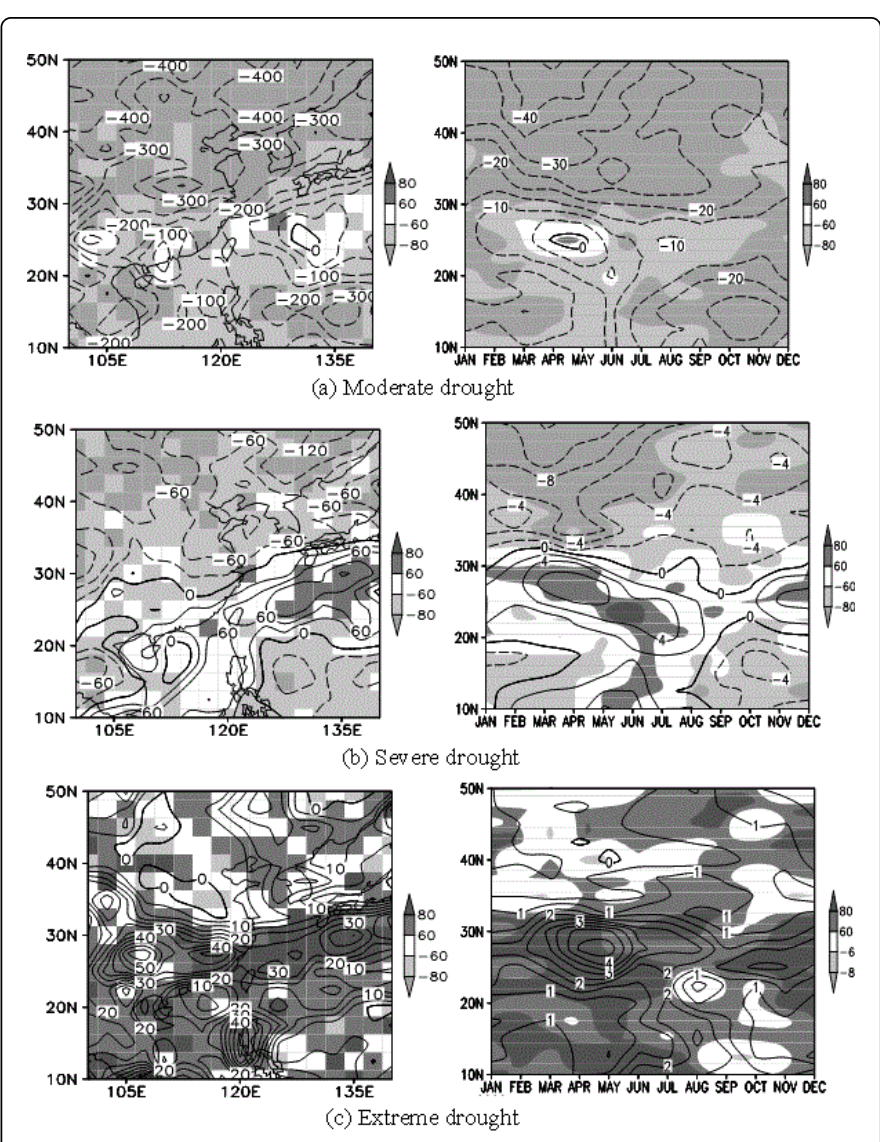

Figure 5: The multi-model ensemble differences in (a) moderate, (b) severe, and (c) extreme drought days between the A1B and the 20C3M experiments. The left panels show the horizontal distribution of the difference in the number of total drought days (days/decade). The right panels show the latitude-time cross-section of the difference in the number of monthly total drought days (days/decade) averaged for $100^{\circ} \mathrm{E}-140^{\circ} \mathrm{E}$. Shading denotes the consistency level (\%) of the 14 models in predicting the direction of change in the number of total drought days.

In the difference map of severe drought days, although, decreases in the drought days are still dominant over Northeast Asia, the model consistency levels become lower compared with that in the moderate case. In the some regions of the Southeast Asia, there is shown an increase of drought days, which are predicted by approximately half of the models. These increases are noteworthy in the areas of $25^{\circ}-30^{\circ} \mathrm{N}$ during winter to spring, and in all Southeast Asia during summer.

Extreme drought days are predicted to increase in all Southeast Asia by the majority of the models. In Northeast Asia, the same reactions appear in some regions. Such an increase of drought days is shown in all seasons in Southeast Asia, especially nearby the regions of $25^{\circ}-30^{\circ} \mathrm{N}$ in spring.

\section{Summary and Conclusion}

We analyzed the changes in precipitation and drought climatology over East Asia by global warming using daily precipitation data from 14 coupled atmosphere-ocean General Circulation Model (GCM) simulations under the SRES A1B scenario at the end of the twenty-first century. The Effective Drought Index (EDI) was applied to measure the drought.

The increase in the mean precipitation was predicted in East Asia by the majority of the models. This is outstanding in Northeast Asia, and in Southeast Asia, the magnitudes of the increase and model consistency levels are relatively small. These increases in the mean precipitation are accompanied by a bigger increase in the precipitation variability. The seasonal precipitation increase is the biggest in Northeast Asia during winter, and shown commonly in East Asia during summer. From the regions around $30^{\circ} \mathrm{N}$ during winter to Southeast Asia during spring, there are weak precipitation decreases.

All GCMs predicted that the frequency of droughts decreases in East Asia according to the increased mean precipitation, and the frequency of wetness increases greatly. However, the frequency of extreme drought also projected to increase due to the greatly increased precipitation variability. That is, the frequency and duration of droughts showed a tendency of decrease, but the precipitation shortage is greater during the drought period. This is because water vapours at troposphere increase according to global warming.

We analyzed the spatial and seasonal changes in the three categories of drought according to the intensity (moderate, severe, and extreme drought). Moderate drought days are predicted to decrease in all East Asia except for regions of $25^{\circ}-30^{\circ} \mathrm{N}$ during short period in spring. This weakening of drought is especially noteworthy in Northeast Asia during winter and spring when precipitation increases greatly. However, severe droughts show almost no change in Southeast Asia, but an increasing tendency during spring and summer in those regions. Extreme droughts projected to increase in all Southeast Asia during all seasons. This strengthening of extreme drought intensity is also shown in some regions of Northeast Asia. This regional difference of drought is because global warming continues to more accelerate over mid-latitude of East Asia.

\section{Acknowledgments}

This work was supported by the R\&D Project of the Korea Meteorological Administration "Development and application of technology for weather forecast".

\section{References}

1. McCarthy JJ, Canziani OF, Leary NA, Dokken DJ, White KS (2001) Climate Change 2001: Impacts, Adaptation and Vulnerability, Cambridge University Press, Cambridge, UK.

2. $\mathrm{Hu} \mathrm{ZZ}$, Latif M, Roeckner E, Bengtsson L (2000) Intensified Asian summer monsoon and its variability in a coupled model forced by increasing greenhouse gas concentrations. Geophys Res Lett 27: 2681-2684.

3. Kimoto M (2005) Simulated change of the East Asian circulation under global warming scenario. Geophys Res Lett, p: 32.

4. Loo YY, Billa L, Singh A (2015) Effect of climate change on seasonal monsoon in Asia and its impact on the variability of monsoon rainfall in Southeast Asia. Geosci Front 6: 817-823.

5. Kripalani RH, Oh JH, Chaudhari HS (2007) Response of the East Asian summer monsoon to doubled atmospheric $\mathrm{CO}_{2}$ : Coupled climate models simulations and projections under IPCC AR4. Theor Appl Climatol 87: $1-28$.

6. Zhi X, Qi H, Bai Y, Lin C (2012) A comparison of three kinds of multimodel ensemble forecast techniques based on the TIGGE data. Acta Meteorol Sin 26: 41-51. 
Citation: Choi JW, Cha Y, Kim JY (2016) Evaluation of Future East Asia Drought Using Multi-Model Ensemble. J Climatol Weather Forecasting 4:

Page 5 of 5

7. Wetherald RT, Manabe S (2002) Simulation of hydrologic changes associated with global warming. J Geophys Res 107: 4379-4394.

8. Manabe S, Wetherald RT, Milly PCD, Delworth TL, Stouffer RJ (2004) Century-scale change in water availability: $\mathrm{CO}_{2}$-quadrupling experiment. Clim Change 64: 59-76.

9. Kiem AS, Austin EK (2013) Drought and the future of rural communities: Opportunities and challenges for climate change adaptation in regional Victoria, Australia. Global Environ Change 23: 1307-1316.

10. Burke EJ, Brown SJ, Christidis N (2006) Modeling the recent evolution of global drought and projections for the twenty-first century with the Hadley Centre climate model. J Hydrometeol 7: 1113-1125.

11. Zhou TJ, Tao H (2015) Projected changes of Palmer Drought Severity index under an RCP8.5 scenario. Atmos Oceanic Sci Lett 5: 273-278.

12. Wang G (2005) Agricultural drought in a future climate: Results from 15 global climate models participating in the IPCC 4th assessment. Clim Dyn 25: 739-753.

13. Byun HR, Wilhite DA (1999) Objective quantification of drought severity and duration. J Clim 12: 2747-2756.

14. Kitoh A, Uchiyama $T$ (2006) Changes in onset and withdrawal of the East Asian summer rainy season by multi-model global warming experiments. J Meteorol Soci Jpn 84: 247-258.
15. Sperber KR, Annamalai H, Kang IS, Kitoh A, Moise A, et al. (2013) The Asian summer monsoon: an inter comparison of CMIP5 vs. CMIP3 simulation of the late 20th century. Clim Dyn 41: 2711-2744.

16. Yamaguchi Y, Shinoda M (2002) Soil moisture modeling based on multiyear observations in the Sahel. J Appl Meteor 41: 1140-1146.

17. Morid S, Smakhtin V, Moghaddasi M (2006) Comparison of seven meteorological indices for drought monitoring in Iran. Int J Climatol 26: 971-985.

18. Smakhtin VU, Hughes DA (2007) Automated estimation and analyses of meteorological drought characteristics from monthly rainfall data, Environ. Model Software 22: 880-890.

19. Akhtari R, Morid S, Mahdian MH, Smakhin V (2009) Assessment of areal interpolation methods for spatial analysis of SPI and EDI drought indices. Int J Climatol 29: 135-145.

20. Kimoto M, Yasutomi N, Yokyama C, Emori S (2005) Projected changes in precipitation characteristics around Japan under the global warming. SOLA 1: 85-88. 